ISSN 2693-2490

\title{
Cognitive and Executive Disorders in Obsessive Compulsive Disorder (OCD) Comorbid with Major Depressive Disorder (MDD) and Evidence of Mindfulness
}

Minotta-Valencia, Lina ${ }^{1 *}$, Minotta-Valencia, Carlos ${ }^{2}$

${ }^{1}$ Medical Universidad de Antioquia. Medellín, Colombia.

${ }^{2}$ Psychologist, medical student Universidad de Antioquia. Msc in psychotherapy Universidad Pontificia Bolivariana. Medellín, Colombia.

\author{
*Correspondence author
}

\author{
Minotta-Valencia, Lina \\ Medical Universidad de Antioquia \\ Medellín \\ Colombia
}

Submitted : 8 Apr 2021 ; Published : 15 Jun 2021

\begin{abstract}
The present text carries out a characterization of the anomalous functioning of cognitive and emotional processes governed by the guidelines of a central dysexecutive control, modulated by persistent, negligent, and sometimes insensitive patterns to command lines of detection of external stimuli and required adjustment of focus according to changing keys of a demanding task-oriented context. Rumination as a metacognitive process, once anarchic, is in a domain-free domain capable of usurping memory and attentional resources by retrieving them to the selfreferential self, making it a preferred focus of relevance. The ruminative process, slipping into the conscious network normally alert, is incessantly overwritten until it colonizes it, makes it neglect its tasks of observation and surveillance, to instead, abstract it from the outside world and overturn it in a kind of inflated self-absorption or hyper-augmented self-consciousness. The cognitive rumination is postulated as the polymorphic process that serves as a base substrate to explain the logic of appearance and maintenance of both obsessive-compulsive disorder and major depression, these diagnostic entities being the expression of the same polymorphic process. Turned to the future in the TOC and to the past in the TDM. Finally, a review is made of the evidence that the practice of mindfulness has reported in reducing rumination.
\end{abstract}

Keywords: Cognitive Rumination, Inattention, Obsessive Disorder, Depressive Disorder, Cognitive Dysfunction, Selfconcept

Introduction

The literature has evidenced the simultaneous concurrence between mood disorders and anxiety for life, as well as cross symptoms in both types of disorders [1,2]. In addition to the high comorbid prevalence of both disorders; the overlap of its clinical manifestations has repercussions in the practice of its treatment, inasmuch as the direction that the course of this takes mediates. In fact, a greater deterioration in quality of life [3] and a lower rate of positive response to cognitive-behavioral treatment have been associated with mixed pathology OCD + MDD [4,5]

Van Balkom, et al. (2008) in a study of 141 outpatients with an anxiety disorder, showed results that indicated less improvement and a lower remission rate in the comorbid group with depression when compared with groups with anxiety, but without comorbidity [6].

It is not unusual for the anxious patient to meet the criteria of an affective disorder in the consultation, on the other hand, it is no less incidental that the depressed patient in turn refers anxious symptoms with sufficient relevance to be framed within a clinical picture $[7,8,9]$. In the study carried out by Sanderson,
DInardo, Rapee, \& Barlow (1990) with 130 patients, 70\% of those diagnosed with an anxiety disorder met criteria for other disorders, among these, $33 \%$ fell into the category of anxiety [10].

On the other hand, the early age of onset of OCD seems to be a crucial factor that defines greater vulnerability to the development of recurrent major depression, and in turn, recurrent MDD, makes the symptoms of OCD more severe, Hong, et al. (2004) see this as an expression of the emotional impact of dealing as an adverse component; the manifestations of OCD in terms of emotional, academic, work and social development $[11,12]$.

Moritz, et al. (2001) showed that when OCD is associated with depression, it impacts executive performance, they studied 36 patients with OCD, dividing them according to the mean score obtained on the Hamilton Depression Scale, those who they scored high on the scale and had worse performance on executive tasks, on the Wisconsin Card Rating, and on verbal fluency tasks [13]. 
Rumination, concerns and executive function in the patient with $\mathrm{OCD}$

Giving structure and order to the fulfillment of tasks in a demanding context requires coordinating actions, this at the behavioral level, as for the cognitive level; it comprises complex planning and memory processes combined. Thus, organizing different plans in an order of priorities requires flexible and adaptive self-regulation, to changing contexts of multiple demands, as well as reasonable demarcation of objectives adjusted to them [14].

\section{Operating memory in the patient with OCD}

Operating memory, rather than being assumed as a drawer where information remains passively stored, occupies an active role in its processing when its usefulness is put to the test. In the obsessive patient, this memory, already susceptible to interference in itself, is even more vulnerable in its ability to facilitate the consolidation of new, initially short-term memories, as they are temporarily processed and stored in "online" use. These results, among other reasons, due to the weight or cognitive and emotional burden exerted by intrusive "usurping" thoughts on the already limited resources of attention and retention in the transitory zone.

One of the difficulties presented in the patient is precisely the dilemma in the central control system in the face of different demands on the one hand, the anticipated worries and threats (losses anticipated in the future) and in turn, those of the immediate task Ideally, it would select recent and useful information to be stored, however, since it is not in control or is deregulated, it fails to allocate resources to attend to pertinent data and to give them prevalence in the processing and subsequent storage.

Attention disturbances, including selective disturbances, affect the ability to consolidate and retrieve memories directed or driven by effort, and to a lesser degree in implicit memory [15]. Not to mention that in free evocation as well as in recognition, key use skills participate, a priming effect is observed, and operations in which attention is a participant [16].

\section{Cognitive background of comorbid anxiety and depressive} phenomenology

In people with a high self-demand quota fueled by super demands divorced from any concessions, the fear and anticipation of failure, the overestimation of the consequences of a 'bad grade', and the 'eternal debt' to them of 'never' reaching the high standards by which this is judged [17], are usually common variables, in the joint scenario of anxiety and depression disorders [18]. The rumination component is linked to the above, with a tendency to a repetitive cycle of negative cognitions sustaining depressive symptoms [19,20,21].

The ruminant cycle in the patient with OCD and MDD and the underlying logic in its maintenance

The retrospective self-awareness examination, for example, of what was done and what "should not have been done", or the examination of what was not done when "it should have been done", that is, self-centered attention on the self, does not diminish in its propensity to obviate the need to accept the reality that the world of now, in which actions are unsuccessfully sought to undo, is different from the world in which they were carried out. It seems to be precisely the impossibility of resolving this discrepancy between the two worlds, which would define the maladaptive condition of rumination, insofar as it is not at the service of solving problems, but rather directed at the 'self' as a compensatory mechanism for regulating rumination. Dysphoric and decompensated affect, the product of experiences experienced as "a failure" by having high standards to achieve and being unable to achieve them $[22,23,24]$.

Factors associated with meanings tinged with anguish about the anguish themselves or a fatalistic meta representation of the feelings of sadness, that is, the awareness of the emotions linked to the representations of the different experiences, it seems to make the patient; more susceptible to pathological suffering in situations of chronic stress and to a self-perception of little control over events, this seems to be especially true, in people whose rumination leads to melancholy [25]. Rumination that can even be implicated in the deterioration of executive functions with or without affectation of the state of mind [26].

In fact, rumination seems to be linked to a higher reactance to stressful events, and its perception as more negative [27]. It constitutes a consistent mode of response; in conducting retrospective evaluations whose attention has been focused on the 'self' with negative bias [28]. Rumiative activity that can be exacerbated after distressing events and be a predictor of these, moreover, in depression it tends to prolong the state of sadness with the concomitant reflection on both the responsibility, its causes, ways of having avoided, and hidden meanings, accompanied by questions like - \{why transcendental $\}$ - [19], adds to this the rumination on the degree of adequacy of one's thoughts and feelings.

Thus, rumination operates as a mode of response linked to a depressed mood with greater self-awareness, either about one's own abilities, attributes of a moral order, or qualities of another nature, self-awareness related to a greater tendency to introspection. Where the patient remains "abstracted" in his own thoughts $[29,30,31,32,33,34,35,36]$. Emphasizing the attention on the "I" over the content of what is perceived, seen, heard, or read.

In the patient with MDD, the negative mood that could well be self-reported as decay, accompanied in turn by "loss of energy", states of inactivity "without doing anything" and with increasing anxious periods, without this starting to action, is fueled by an incisive tendency of self-focused reflection, tinged with qualifications and self-reported judgments, in which the patient is taken as the object of negative and critical evaluation, evident in recurrent and persistent errors, setting up a constant pattern of thinking styles that fuel feelings of hopelessness [37,38,21,39]. In fact, self-care in a setting of depression and little expectation of achievement could be 
linked to a real performance deficit, which would make the patient more vulnerable to the emission of confirmation biases [40].

Thus, the stream of negative images and cognitions of an incisive nature, bundled with memories, concerns, scenarios of present or future problems, is usually a process inscribed in disorders of both anxiety, depression and insomnia [41]. Manifested as a chain of thoughts that monopolizes spaces of time both for recreation and in the course of different occupations or tasks, the patient being impelled to spin in circles and dead ends; repeated series of contents of meanings given to concern that border on the edge of the control mechanisms to stop them. Regarding the self-concept, fixed, global representations of the 'self' are again and again ratified by feeding back on negative emotional states, which, in turn, it also feeds, selectively assimilating fragments of information congruent with punishments, making use of resources attention and memory, thus increasing the self-absorption that neglects external stimuli.

In sum, rumination and repetitive thoughts are a vulnerability factor that makes a person prone to developing depression for a longer time, and anxiety symptoms more interfering with daily activities. Thus, this is consistent with the previous literature $[42,43,44,45,46,47]$.

\section{Mindfulness training}

Conscious self-knowledge, in the context of a mindfulness practice, has been shown to reduce the risk of relapse in major depressive episodes [48], in addition, dispositional mindfulness provides a context in which to be able to reevaluate negative emotional experience, it allows to reduce activation tonsillar, and self-focused processing of the predetermined network at rest [49], among other correlates have been found increased conscious and emotional regulatory control of selfcriticism [50], increased general sense of well-being [51,52], increasing enabling self-compassion of a decoupling between a negative result and emotional reactivity to the perception of it [53], reduces cognitive reactivity to sad mood [54], reduces rumination and perceived stress $[55,56]$, prevents alterations in working memory in relation to the effects of stress and high negative affect [57,58] and improves its measures [59] while reducing distraction. Mental on [60] through the training component in acceptance or receptive and open mind [61].

The practice of Mindfulness in the therapeutic and / or preventive sphere has reported effectiveness data in reducing depression symptoms, preventing relapses, as well as offering protection mechanisms against the trait rumination process, favoring the reduction of emitted biases, emotional regulation, less insular automatic reactivity to negative stimuli. These results are attributed to the possibility offered by the exercise of mindfulness techniques; of distancing oneself from internal experience, with receptive attention to its own stimuli, in a conscious here and now, even modifying existential ways of perceiving the 'I' and reality that transcend fixed selfreferential processing biases, in a broader context of practices contemplative $[62,63,64,65]$.

Effects at the level of brain functional networks, confirmed by neuroimaging techniques and magnetic resonance imaging [66], amygdala, hippocampus, lateral frontal regions [67], and even neruoanatomic structural modification in terms of increased gray matter of the right insula are also verified. [68], transformations in the graphic topology of the brain connectome at the network level and its connecting forces in the insula favoring interoceptive processes [69], mitigating the effects of stress and reducing cortisol levels [70].

Mindfulness has positively correlated its self-reported practice with cognitive processes of self-control [71], working memory underlying executive function [71,72]. Mindfulness training for stress reduction has shown changes in morphological thickness indices of both the insular cortex and the somatosensory cortex [73].

This intentional meta-consciousness of mental events that are spontaneous and meditative, would offer greater control over the thought processes themselves, not by means of their repression or attempted suppression, but by ceasing the struggle to contain them, they adopt a lower negative valence [74].

Faced with emotional stimuli of aversive nature, the experienced training affecting areas of the 'network by default' has succeeded in inhibiting the intensity of the posterior medial-cingulate prefrontal interconnection [75,76,77,78]. Of mantras, in studies of RMRI dependent on the level of oxygenation, shows a reduction with respect to the basal resting state of the MND activity.

In short, going through different levels of consciousness, allows to reach a point in which one "becomes aware of ...", creates a different reality of the experience, and therefore a different experience in turn. Putting in parentheses, the very reality of the experience, cracks its apparently solid foundations, manifesting itself in its splendor, imminently empty of an immutable essence.

\section{Conclusions}

The present study has taken rumination as the central process involved both in the initiation and maintenance of depressive symptoms, whose persistent and self-perpetuating cycle makes them a chronic and refractory condition [79]. Therefore, a treatment proposal must be designed tending to promote in the patient a modality of thought oriented towards the achievement of goals, no longer immersed in general and abstract self-drive wanderings related to the ' $I$ ' framed in labyrinths without resolution [80,47, 81.82.46.83].

Taking into account the above, it is feasible to combine the process of rumination associated with recurrent depression $[44,84]$ and repetitive negative thinking of worry; link it to OCD [85] in a transdiagnostic formulation that makes it possible to treat simultaneously, simultaneously, both the 
constellation of symptoms of recurrent depressive disorder and obsessive disorder in the same patient, insofar as both constructs have shown presence and overlap [86] -although not to the same degree in both disorders-, and this to such an extent that in the present study they are assumed -with regard to formulation and treatment-; as two variants of the same process [87], whose difference responds not so much to the form of the process but to its content, one aimed at recreating the past rumination-depression, and the other inclined to future uncertainty scenarios, worry-anxiety. Finding that rumination contributes to concern by making the imagination of positive futures less likely [88].

\section{References}

1. Crino, R., \& Andrews, G. (1996) Obsessive-compulsive disorder and axis I comorbidity. Journal of Anxiety Disorders, 10(1): 37-46.

2. Seligman, L., \& Ollendick, T. (1998) Comorbidity of Anxiety and Depression in Children and Adolescents: An Integrative Review. Clinical Child and Family Psychology Review, 1(2): 125-144.

3. Masellis, M., Rector, N. A., \& Richter, M. A. (2003) Quality of Life in OCD: Differential Impact of Obsessions, Compulsions, and Depression Comorbidity. The Canadian Journal of Psychiatry, 48(2): 72-77.

4. 4. Abramowitz, J. (2004). Treatment of obsessivecompulsive disorder in patients who have comorbid major depression. Journal of Clinical Psychology, 60(11): 11331141.

5. Abramowitz, J., Franklin, M., Street, G., \& Foa, E. B. (2000) Does comorbid major depressive disorder influence outcome of exposure and response prevention for OCD. Behav Ther, 517-528.

6. van Balkom, A., van Boeijen, C., Boeke, A., van Oppen P., P., Kempe MA, P., \& van Dyck, R. (2008) Comorbid depression, but not comorbid anxiety disorders, predicts poor outcome in anxiety disorders. Depression and anxiety The Official Journal of ADAA, 25(5): 408-415.

7. Jack, M., \& Gorman, M. D. (1997) Comorbid depression and anxiety spectrum disorders. Depression and anxiety, 160-168.

8. Brown, T., \& Barlow, D. (1992) Comorbilidad entre los trastornos de ansiedad: implicaciones para el tratamiento y DSM-IV. Revista de Consultoría y Psicología Clínica, 60(6): 835-844.

9. Clark, L. A., \& Watson, D. (1991) Tripartite model of anxiety and depression: Psychometric evidence and taxonomic implications. Journal of Abnormal Psychology, 100: 316-336.

10. Sanderson, W., DInardo, P., Rapee, R., \& Barlow, D. (1990) Syndrome comorbidity in patients diagnosed with a DSM-III-R anxiety disorder. Journal of Abnormal Psychology, 99(3): 308-312.

11. Hong, J., Samuels, J., Bienvenu, O., Cannistraro, P., Grados, M., Riddle, M., Nestadt, G. (2004) Clinical correlates of recurrent major depression in obsessivecompulsive disorder. Depression and anxiety, 86-91.
12. Norberg, M., Diefenbach, G., \& Tolin, D. (2008) Quality of life and anxiety and depressive disorder comorbidity. Journal of Anxiety Disorders, 22(8): 1516-1522.

13. Moritz, S., Birkner, C., Jacobsen, D., Fricke, S., Bothern, A., \& Hand, I. (2001) Impacto de los síntomas depresivos comórbidos en el rendimiento neuropsicológico en el trastorno obsesivo-compulsivo. Journal of Abnormal Psychology, 653-657.

14. Tirapu-Ustárroz, J., García-Molina, A., Luna-Lario, P., Roig-Rovira, T., \& Pelegrín-Valero, C. (2008) Modelos de funciones y control ejecutivo. Revista de neurología, 46(11): 684-692.

15. Ballesteros, S., Reales, J. M., García, E., \& Carrasco, M. (2006) Selective attention effects on implicit and explicit memory for familiar objects at diferent delay conditions. Psicothema, 96-107.

16. Ballesteros, S., Reales, J. M., Mayas, J., \& Heller, M. A. (2008) Selective attention modulates visual and haptic repetition priming: Effects on aging and Alzheimer disease. Experimental Brian Research, 473-483.

17. Hewitt, P. L., Flett, G. L., \& Ediger, E. (1996) Perfectionism and depression: Longitudinal assessment of specific vulnerability hypothesis. Journal of Abnormal Psychology, 276-280.

18. Engan, S. J., Wade, T. D., \& Safran, R. (2012) The transdiagnostic of perfectionism. Revista de Psicopatología y Psicología Clínica, 279-294.

19. Nolen-Hoeksema, S. (2000) The role of rumination in depressive disorders and mixed anxiety/depressive symptoms. Journal of Abnormal Psychology, 109: 504511.

20. Ferrer, L., Martín-Vivar, M., Pineda, D., Sandín, B., \& Piqueras, J.A. (2018) Relación de la ansiedad y la depresión en adolescentes con dos mecanismos transdiagnósticos: el perfeccionismo y la rumiación. Behavioral Psychology/ psicología Conductual, 26(1).

21. González, M., Ibáñez, I., \& Barrera, A. (2017) Rumiación, preocupación y orientación negativa al problema: procesos transdiagnósticos de los trastornos de ansiedad, de la conducta alimentaria y del estado de ánimo. Acta Colombiana de Psicología, 20(2): 30-41.

22. Carver, C. S., \& Scheier, M. F. (1981) Attention and selfregulation: A control-theory approach to human behavior. New York: Springer.

23. Lewinsohn, P. M., Hoberman, H., Teri, L., \& Hautzinger, M. (1985) An integrative theory of depression. En S. Reiss, \& R. Bootzin, Theoretical issues in behavior therapy. Orlando: Fl: Academic Press. págs. 331-359.

24. Martin, L. L., \& Tesser, A. (1989) Toward a motivational and structural theory of ruminative thought. En J. S. Uleman, \& J. A. Bargh, Unintended thought. New York: Guilford Press. págs. 306-326.

25. Nolen-Hoeksema, S., Larson, J., \& Grayson, C. (1999) Explaining the gender difference in depressive symptoms. Journal of Personality and Social Psychology, 77(5): 1061-1072.

26. Martin, Leonard L., and Abraham Tesser (1996) "Some ruminative thoughts." Advances in social cognition 9 (1996): 1-47. 
27. Moberly, N. J., \& Watkins, E. R. (2008) Ruminative SelfFocus and Negative Affect: An Experience Sampling Study. (A. MacDonald, Ed.) Journal of Abnormal Psychology, 117(2): 314-323.

28. Wood, J. V., Saltzberg, J. A., \& Goldsamt, L. A. (1990) Does Affect Induce Self-Focused Attention. Journal of Personality and Social Psychology, 58(5): 899-908.

29. Pyszczynski, T., Kathleen, H., \& Greenberg, J. (1987) Depression, Self-Focused Attention, and Expectancies for Positive and Negative Future Life Events for self and others. Journal of Personality and Social Psychology, 52(5): 994-1001.

30. Pyszczynski, T., \& Greenberg, J. (1987) Self-regulatory perseveration and the depressive self-focusing style: A self-awareness theory of the development and maintenance of depression. Psychological Bulletin, 102: 122-138.

31. Pyszczynski, T., \& Greenberg, J. (1986) Evidence for a depressive self-focusing style. Journal of Research in Personality, 20: 95-106.

32. Wood, J. V., Saltzberg, J. A., Neale, J. M., Stone, A. A., \& Rachmiel, T. B. (Junio de 1990) Self-focused attention, coping responses, and distressed mood in everyday life. Journal of Personality and Social Psychology, 58(6): 1027-1036.

33. Mor, N., \& Winquist, J. (2002) Self-Focused Attention and Negative Affect: A Meta-Analysis. Psychological Bulletin, 128(4): 638-662.

34. Moberly, N. J., \& Watkins, E. R. (2008) Rumiative selffocus; negative life events and negative affect. Behaviour Research and therapy, 46(9), 1034-1039.

35. Ingram, R. E., Lumry, A. E., Cruet, D., \& Sieber, W. (1987). Attentional processes in depressive disorders. Cognitive Therapy and Research, 11(3): 351-360.

36. Sakamoto, S. (2000) Self-focusing situations and depression. The Journal of social psychology, 140(1): 107-108.

37. Sanjuán, P., Pérez-García, A. M., Rueda, B., \& Ángeles, R. (2008) Estilos explicativos y afecto negativo. Revista de Psicopatología y psicología Clínica, 13(1): 45-52.

38. Lyubomirsky, S., Tucker, K. L., Caldwell, N. D., \& Berg, K. (1999) Why ruminators are poor problem solvers: clues from the phenomenology of dysphoric rumination. Journal of personality and social psychology, 77(5): 1041-1060.

39. Ciesla, J. A., \& Roberts, J. E. (2007) Rumination, negative cognition, and their interactive effects on depressed mood. Emotion, 7(3): 555-565.

40. Strack, S., Blaney, P. H., Ganellen, R. J., \& Coyne, J. C. (1985). Pessimistic self-preoccupation, performance deficits and depression. Journal of personality and social psychology, 49(4): 1076-1085.

41. Ehring, T., \& Watkins, E. R. (2008) Repetitive Negative Thinking as a Transdiagnostic Process. International Journal of Cognitive Therapy, 1(3): 192-205.

42. Wegner, D. M., Schneider, D. J., Carter, S. R., \& White, T. L. (1987) Paradoxical effects of thought suppression. Journal of Personality and Social Psychology, 53: 5-13.

43. Wegner, D. M., Erber, R., \& Zanakos, S. (1993) Ironic processes in the mental control of mood and mood-related thought. Journal of Personality and Social Psychology, 65(6): 1093-1104.

44. Just, N., \& Alloy, L. B. (1997) The response styles theory of depression tests and an extension of the theory. Journal of Abnormal Psychology, 106: 221-229.

45. Kuehner, C., \& Weber, I. (1999) Responses to depression in unipolar depressed patients: An investigation of Nolen-Hoeksema's response styles theory. Psychological Medicine, 29: 1323-1333.

46. Watkins, E. R. (2009) Depressive Rumination: Investigating Mechanisms to Improve Cognitive Behavioural Treatments. Cognitive Behaviour Therapy, 38: 8-14.

47. Takano, K., \& Tanno, Y. (2010) Concreteness of thinking and self-focus. Consciousness and cognition, 19(1): 419425.

48. Huffziger, S., \& Kuehner, C. (2009). Rumination, distraction, and mindful self-focus in depressed patients. Behaviour research and therapy, 47(3): 224-230.

49. Camino, B. N., Creswell, J. D., Eisenberger, N. I., \& Lieberman, M. D. (2010) Dispositional mindfulness and depressive symptomatology: correlations with limbic and self-referential neural activity during rest. Emotion, 10(1): $12-24$.

50. Lutz, J., Brühl, A. B., Doerig, N., Scheerer, H., Achermann, R., Weibel, A., Herwig, U. (2016) Altered processing of self-related emotional stimuli in mindfulness meditators. Neuroimage, 124: 958-967.

51. Deyo, M., Wilson, K. A., Ong, J., \& Koopman, C. (2009) Mindfulness and rumination: does mindfulness training lead to reductions in the ruminative thinking associated with depression? Explore, 5(5): 265-271.

52. Carmody, J., Baer, R. A., LB Lykins, E., \& Olendzki, N. (2009) An empirical study of the mechanisms of mindfulness in a mindfulness-based stress reduction program. Journal of clinical psychology, 65(6): 613-626.

53. Kuyken, W., Watkins, E., Holden, E., White, K., Taylor, R. S., Byford, S., Dalgleish, T. (2010) How does mindfulnessbased cognitive therapy work. Behaviour research and therapy, 48(11): 1105-1112.

54. Raes, F., Dewulf, D., Van Heeringen, C., \& Williams, J. M. (2009) Mindfulness and reduced cognitive reactivity to sad mood: evidence from a correlational study and a non-randomized waiting list controlled study. Behaviour research and therapy, 47(7): 623-627.

55. Shapiro, S. L., Oman, D., Thoresen, C. E., Plante, T. G., $\&$ Flinders, T. (2008) Cultivating mindfulness: effects on well-being. Journal of clinical psychology, 64(7): 840862.

56. Goyal, M., Singh, S., Sibinga, E. M., Gould, N. F., Rowland-Seymour, A., Sharma, R., Haythornthwaite, J. A. (2014) Meditation programs for psychological stress and well-being: a systematic review and meta-analysis. JAMA Intern Med, 174(3): 357-368.

57. Banks, J. B., Welhaf, M. S., \& Srour, A. (2015). The protective effects of brief mindfulness meditation trining. Consciousness and cognition, 33: 277-285. 
58. Jha, A. P., Stanley, E. A., Kiyonaga, A., Wong, L., \& Gelfand, L. (2010) Examining the protective effects of mindfulness training on working memory capacity and affective experience. Emotion, 10(1): 54.

59. Lao, S. A., Kissane, D., \& Meadows, G. (2016). Cognitive effects of MBSR/MBCT: A systematic review of neuropsychological outcomes. Consciousness and cognition, 45: 109-123.

60. Jha, A. P., Stanley, E. A., Kiyonaga, A., Wong, L., \& Gelfand, L. (2010) Examining the protective effects of mindfulness training on working memory capacity and affective experience. Emotion, 10(1): 54.

61. Rahl, H. A., Lindsay, E. K., Pacilio, L. E., Brown, K. W., \& Creswell, J. D. (2017) Brief mindfulness meditation training reduces mind wandering: the critical role acceptance. Emotion, 17(II): 224-230.

62. Dorjee, D. (2016). Defining Contemplative Science: The Metacognitive Self-Regulatory Capacity of Mind, Context of Meditation Practice and Modes of Existencial Awareness. Front. Psychol, 7(I-15).

63. Crane, R. S., Brewer, J., Feldman, C., Kabat-Zinn, J., Santorelli, S., Williams, J. M., \& Kuyken, W. (2017) What defines mindfulness-based programs? The warp and the weft. Psychological medicine, 47(6): 990-999.

64. Vago, D. R., \& Silbersweig, D. A. (2012). Self-awareness, self-regulation, and self-transcendence (S-ART): a framework for understanding the neurobiological mechanisms of mindfulness. Frontiers in Human Neuroscience, 6(296).

65. Xiao, Q., Yue, C., He, W., \& Yu, J. Y. (2017). The Mindful Self: A Mindfulness-Enlightened Self-view. Frontiers in psychology, 13(8): 1752.

66. Paul, N. A., Stanton, S. J., Greeson, J. M., Smoski, M. J., \& Wang, L. (2013). Psychological and neural mechanisms of trait mindfulness in reducing depression vulnerability. Social cognitive and affective neuroscience, 8(1): 56-64.

67. Marchand, W. R. (2014) Neural mechanisms of mindfulness and meditation: Evidence from neuroimaging studies. World journal of radiology, 6(7): 471-479.

68. Murakami, H., Nakao, T., Matsunaga, M., Kasuya, Y., Yamada, J., \& Ohira, H. (2012). The structure of mindful brain. PloS One, 7(9): e46377.

69. Sharp, P. B., Sutton, B. P., Paul, E. J., Sherepa, N., Hillman, C. H., Cohen, N. J., \& Barbey, A. K. (2018) Mindfulness training induces structural connectome changes in insula networks. Scientific reports, 8(1): 1-10.

70. Bergeron, C. M., Almgren-Doré, I., \& Dandeneau, S. (2016). "Letting Go" (Implicitly): Priming Mindfulness Mitigates the Efects of Moderate Social Stressor. Frontiers in psychology, 7(872).

71. Tang, Y.-Y., Hölzel, B. K., \& Posner, M. I. (2015) The neuroscience of mindfulness meditation. Nature Reviews Neuroscience, 16: 213-225.

72. Black, D. S., Semple, R. j., Pokhrel, P., \& Grenard, J. L. (2011) Component Processes of Executive FunctionMindfulness, Self-control, and Working Memory-and Their Relationships with Mental and Behavioral Health. Mindfulness, 2(3): 179-185.
73. Zeidan, F., Johnson, S. K., Diamond, B. J., David, Z., \& Goolkasian, P. (2010). Mindfulness meditation improves cognition: evidence of brief mental training. Consciousness and cognition, 19(II): 597-605.

74. Santarnecchi, E., D’Arista, S., Egiziano, E., Gardi, C., Petrosino, R., Vatti, G., Rossi, A. (2014) Interaction between neuroanatomical and psychological changes after mindfulness-based training. PloS One, 9(10): e0129754.

75. Kieran, C. R., \& Christoff, K. (2014). Metacognitive Facilitation of Spontaneous Thought Processes: When Metacognition Helps the Wandering Mind Find Its Way. En S. Fleming, \& C. Frith, The Cognitive Neuroscience of Metacognition. Berlin Heidelberg: Springer-Verlag. págs. 293-319.

76. Taylor, V. A., Grant, J., Daneault, V., Scavone, G., Breton, E., Roffe-Vidal, S., Beauregard, M. (2011) Impact of mindfulness on the neural responses to emotional pictures in experienced and beginner meditators. NeuroImage, 57(4): 1524-1533.

77. Lutz, J., Brühl, A. B., Scheerer, H., Jäncke, L., \& Herwig, U. (2016). Neural correlates of mindful self-awareness in mindfulness meditators and meditation-naïve subjects revisited. Biological Psychology, 119: 21-30.

78. Berkovich-Ohana, A., Wilf, M., Kahana, R., Arieli, A., \& Malach, R. (2015). Repetitive speech elicits widespread deactivation in the human cortex: the "Mantra" effect? Brain and Behavior, 5(7): I-13.

79. Mennin, D. S., \& Fresco, D. M. (2013) What, Me Worry and Ruminate About DSM-5 and RDoC? The Importance of Targeting Negative Self-Referencial Processing. Clinical Psychology Science and Practice, 20(3): 258267.

80. Watkins, E. R., Baeyens, C. B., \& Read, R. (2009) Concreteness training reduces dysphoria: Proof-ofprincipe for repeated cognitive bias modification in depression. Journal of Abnormal Psychology, 118(1): 5564.

81. Carver, C. S. (1998) Generalization, adverse events, and development of depressive symptoms. Journal of Personality, 66: 607-619.

82. Carver, C. S., \& Ganellen, R. J. (1983) Depression and components of self punitiveness: High standards, selfcriticism, and overgeneralization. Journal of Abnormal psychoogy, 92: 330-337.

83. Kuehner, C., \& Weber, I. (1999) Responses to depression in unipolar depressed patients: An investigation of Nolen-Hoeksema's response styles theory. Psychological Medicine, 29: 1323-1333.

84. Amir, N., Cashman, L., \& Foa, E. B. (1997) Strategies of thought control in obsessive-compulsive disorder. Behaviour Research and Therapy, 35: 775-777.

85. Abramowitz, J. S., Whiteside, S., Kalsy, S. A., \& Tolin, D. F. (2003) Thought control strategies in obsessivecompulsive disorder: A replication and extension. Behaviour Research and Therapy, 41: 529-540.

86. Fresco, D. M., Frankel, A. N., Mennin, D. S., Turk, C. L., \& Heimberg, R. G. (2002) Distinct and overlapping features of rumination and worry: The relationship of cognitive 
production to negative affective states. Cognitive Therapy and Research, 26: 179-188.

87. Segerstrom, S. C., Tsao, J. I., Alden, L. E., \& Craske, M. G. (2000) Worry and rumination: Repetitive thought as a concomitant and predictor of negative mood. Cognitive Therapy and Research, 24: 671-688.

88. Lavender, A., \& Watkins, E. (2004) Rumination and future thinking in depression. British Journal of Clinical Psychology, 43(2): 129-142.

Copyright: (C2021 Minotta-Valencia, Lina. This is an open-access article distributed under the terms of the Creative Commons Attribution License, which permits unrestricted use, distribution, and reproduction in anymedium, provided the original author and source are credited. 